\title{
Relação da granulometria do solo e morfologia do saprolito com a infiltração de água em Neossolos Regolíticos do rebordo do Planalto do Rio Grande do Sul
}

\author{
Relationship between soil size particle distribution and saprolite morphology with water infiltration in \\ Neossolos Regolíticos (Regossols) in the Rio Grande do Sul Plateau edge
}

\author{
Sidinei Leandro Klöckner Stürmer ${ }^{\mathrm{I}}$ Ricardo Simão Diniz Dalmolin ${ }^{\mathrm{II}}$ Antônio Carlos de Azevedo ${ }^{\mathrm{III}}$ \\ Fabrício de Araújo Pedron ${ }^{\text {II }}$ Fabio Pacheco Menezes ${ }^{I V}$
}

RESUMO

Os Neossolos Regolíticos apresentam baixo potencial de uso devido a sua pequena profundidade efetiva, à presença de pedregosidade/rochosidade, ao contato lítico próximo à superfície e à ocorrência frequente em terrenos declivosos. Análises mais detalhadas são necessárias para a melhor interpretação desses solos, visto que a filtragem da água de percolação, retenção de solutos e fluídos e sua possível transformação são de interesse ambiental. Nesse sentido, este estudo gerou informações sobre a infiltração de água em cinco áreas de Neossolos Regolíticos, na região do Rebordo do Planalto do Rio Grande do Sul. Para cada área foram descritos e analisados três perfis, sendo a infiltração de água determinada pelo método dos duplos anéis concêntricos. Mesmo com idêntica classificação taxonômica até o quarto nível categórico, os Neossolos apresentaram variações no seu comportamento hídrico, inclusive quando comparados entre os perfis do mesmo ponto de coleta. Os dados sugerem que a infiltração, nesses Neossolos, é influenciada pela configuração de fraturas do saprolito, granulometria, condições de relevo e uso do solo.

Palavras-chave: solos pedregosos, profundidade efetiva, percolação, morfologia de solos.

\section{ABSTRACT}

Neossolos Regolíticos (Regosols) are fragile from a natural resource perspective because of their small depth, stones and/or rocks presence, near surface lithic contact, fractures in saprolite and frequent occurrence in steep slopes. These soils requires more specific analysis for a better interpretation of their capacity to filtrate water, retain and transform solute and fluids, contributing to the maintenance of the water quality that reaches the groundwater. In that sense, this study generates information on water infiltration in five areas from the the Rio Grande do Sul plateau edge. Three profiles were described and analyzed for each Regosol and the water infiltration was performed whit the double rings method. Even showing the same taxonomic classification, the Regosols showed hydraulic variation behavior, even though when compared among the profiles from the same location. The data suggest that the water infiltration in the Regosols is affected by the saprolite fracture configurations, granulometry, relief conditions and soil use.

Key words: stony soils, effective depth, percolation, soil morphology.

\section{INTRODUÇÃO}

Os Neossolos Regolíticos, devido a sua pequena profundidade efetiva, à grande pedregosidade e/ou rochosidade e à presença de contato lítico próximo à superfície, são solos que possuem potencial de uso fortemente influenciado pelo grau de intemperismo e pela presença de camada saprolítica no perfil (OLIVEIRA, 2001; PEDRON et al., 2009), visto que a água subsuperficial, em sua quase totalidade, interage de alguma forma com a coluna de solo e com o saprolito. Assim, a filtragem da água de percolação, retenção de solutos e fluídos, inclusive antrópicos, e sua possível transformação são de especial interesse na manutenção da qualidade da água que atinge os reservatórios subterrâneos.

'Programa de Pós-graduação em Ciência do Solo, Universidade Federal do Rio Grande do Sul (UFRGS), Porto Alegre, RS, Brasil. "Departamento de Solos, Universidade Federal de Santa Maria (UFSM), 97105-900, Santa Maria, RS, Brasil. E-mail: dalmolin@pesquisador.cnpq.br. *Autor para correspondência.

"IIDepartamento de Ciência do Solo, Escola Superior de Agricultura Luiz de Queiroz (ESALQ), Universidade de São Paulo (USP), Piracicaba, SP, Brasil.

IvPrograma de Pós-graduação em Ciência do Solo, UFSM, Santa Maria, RS, Brasil. 
Nas áreas de encostas do Rebordo do Planalto do Rio Grande do Sul (RS), predominam os Neossolos Litólicos e Neossolos Regolíticos (STRECK et al., 2008). Conforme o mapa de reconhecimento de solos do RS (BRASIL, 1973), essas áreas totalizam aproximadamente $12 \%$ do Estado, caracterizando-se pelas declividades acentuadas e pela cobertura de floresta natural associada à exploração agrícola familiar. O aumento da pressão de uso das terras de encostas no RS e a carência de informações específicas sobre o comportamento dos Neossolos Regolíticos têm demandado pesquisas que são fundamentais para o subsídio do planejamento racional de uso dessas terras (PEDRON, 2007).

Nesse sentido, o conhecimento do comportamento da água no perfil de solo é importante porque contribui no entendimento dos processos pedogenéticos e da movimentação de poluentes no perfil (WHITE \& BRANTLEY, 1995). Nesse contexto, este estudo teve como objetivos determinar a infiltração de água em cinco áreas onde ocorrem Neossolos Regolíticos, na região do rebordo do Planalto do RS, e fazer relações com a granulometria e o fraturamento da camada saprolítica no perfil.

\section{MATERIAL E MÉTODOS}

Desenvolveu-se o presente trabalho de pesquisa em cinco áreas de ocorrência de Neossolos Regolíticos, descritos conforme a seguir: N1, com relevo forte ondulado, altitude de $235 \mathrm{~m}$ e mata natural; $\mathrm{N} 2$, com relevo forte ondulado, altitude de $218 \mathrm{~m}$ e campo nativo; N3, com relevo plano, altitude de $228 \mathrm{~m}$ e campo nativo; N4, com relevo ondulado, $425 \mathrm{~m}$ de altitude e mata nativa e N5, com relevo ondulado, 425 de altitude e vegetação secundária, sendo analisados três perfis (P1, P2 e P3) em cada área. Todas essas áreas estão localizadas na encosta do rebordo do Planalto do RS - área de transição entre a Depressão Central e o Planalto Gaúcho, entre as seguintes coordenadas: $29^{\circ} 32,8^{\prime} / 29^{\circ} 38,7^{\prime}$ Sul e $53^{\circ} 44,8^{\prime} / 53^{\circ} 51,4^{\prime}$ Oeste.

Na área de estudo, o clima predominante, de acordo com a classificação climática proposta por Köeppen, é Cfa II, caracterizado como clima subtropical, úmido sem estiagem, com temperatura média anual de 19,2 C (MALUF, 2000). A precipitação pluviométrica média anual é de $1708 \mathrm{~mm}$, sendo, normalmente, bem distribuída durante as estações do ano.

A descrição morfológica dos perfis e a coleta das amostras para classificação foram realizadas de acordo com SANTOS et al. (2005). Os perfis foram classificados conforme o Sistema Brasileiro de
Classificação de Solos-SiBCS (EMBRAPA, 2006). Todos os solos estudados foram classificados como Neossolo Regolítico Eutrófico típico.

A taxa de infiltração de água no solo foi determinada pelo método dos duplos cilindros concêntricos, segundo metodologia descrita por EMBRAPA (1997). As leituras foram tomadas a um, cinco, 10, 15, 20, 30, 45, 60, 90, 120, 150 e 180 minutos após o início do teste. Ajustou-se o modelo de Kostiakov para a lâmina infiltrada e para a taxa de infiltração, definindo-se como infiltração básica do solo o instante em que a declividade da curva de infiltração de água no solo equivaleu a $-0,01 \mathrm{~cm} \mathrm{~h}^{-1}$ minuto $^{-1}$ (CAUDURO \& DORFMAN, 1986).

As amostras dos horizontes A foram secas ao ar e separadas nas frações grosseira $(>2 \mathrm{~mm})$ e fina $(<2 \mathrm{~mm})$. A granulometria da fração fina foi determinada pelo método da pipeta de acordo com EMBRAPA(1997), utilizando-se o hidróxido de sódio como dispersante químico.

Nos perfis amostrados, também foi realizada a mensuração do fraturamento da camada saprolítica. Foram descritos os ângulos das fraturas do saprolito em relação ao plano gravitacional, o número e a espessura das fraturas que interceptam duas linhas horizontais espaçadas a $20 \mathrm{~cm}$ uma da outra num quadrado de $40 \mathrm{~cm}$ x $40 \mathrm{~cm}$ e o preenchimento das fraturas. Os ângulos das fraturas foram descritos com o auxílio de um transferidor acoplado a um nível de bolha, e a espessura das fraturas foi descrita com um paquímetro (STÜRMER, 2008). A borda superior do quadro utilizado para a determinação das fraturas foi colocada no limite superior da camada $\mathrm{Cr}$ do perfil de solo. Nesse sentido, a determinação do fraturamento ocorreu a 10 e a $30 \mathrm{~cm}$ do limite superior da camada Cr.

Para a análise estatística, foi utilizado o software Canoco for Windows 4.5 (ter BRAAK \& SMILAUER, 2002), utilizando-se a metodologia da análise dos componentes principais, que permite, com base em uma matriz de semelhança, verificar as relações entre os diversos componentes que atuam na infiltração de água no solo.

\section{RESULTADOS E DISCUSSÃO}

Na figura 1A, pode-se observar que, durante toda a avaliação, a taxa de infiltração e a infiltração acumulada de água para o Neossolo 1 (N1) foram maiores no P3, em relação ao P1 e P2, contudo, sem grande diferença entre os perfis amostrados. Transcorridos 180 minutos após o início da determinação da infiltração, o P3 apresentou uma lâmina de água infiltrada de $2077 \mathrm{~mm}$, enquanto que no P2 a 


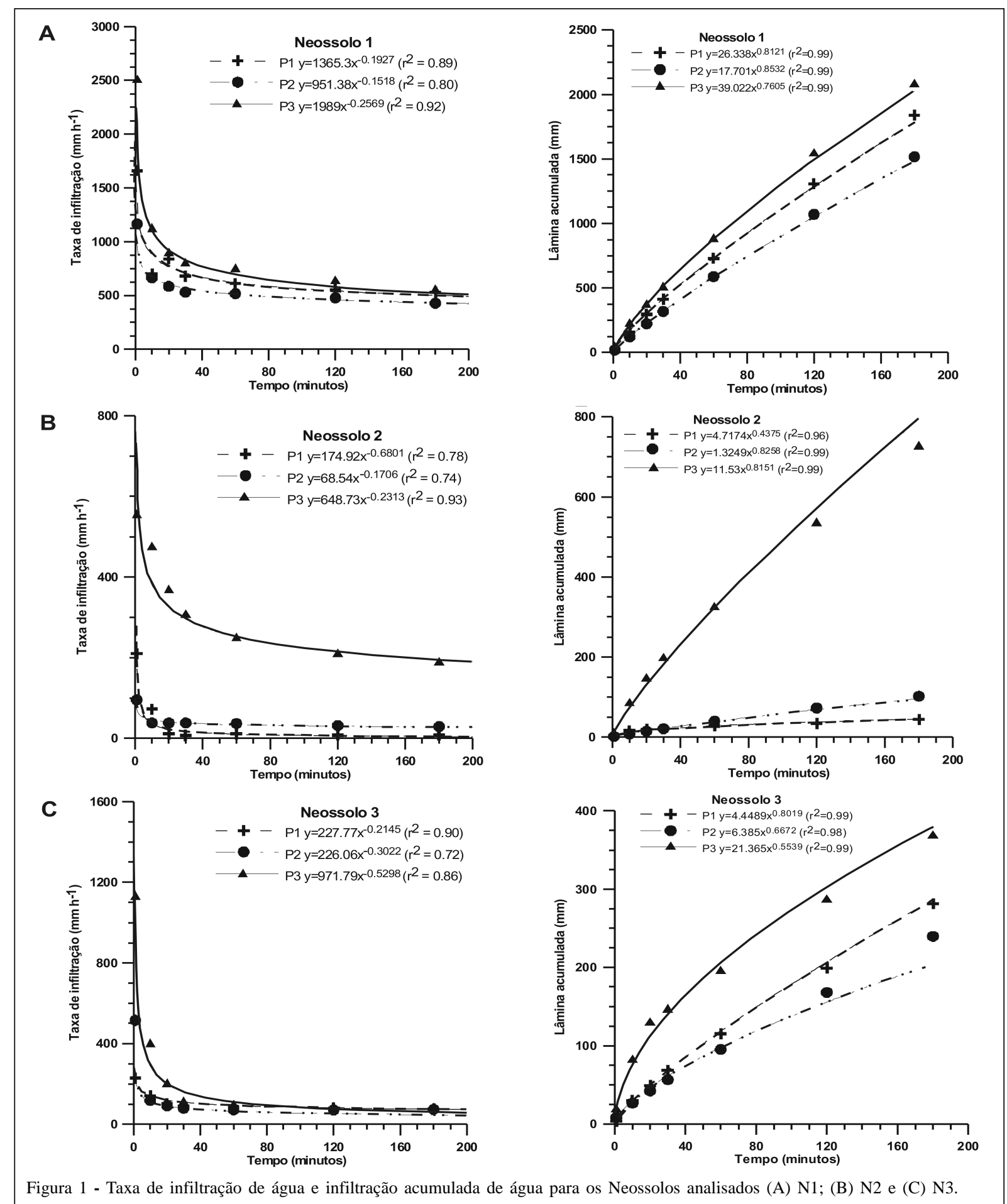

lâmina foi de $1516 \mathrm{~mm}$, uma diferença de aproximadamente $560 \mathrm{~mm}$ entre os perfis com maior e menor infiltração acumulada. A taxa de infiltração básica calculada para os três perfis foi de 347, 365 e $556 \mathrm{~mm} \mathrm{~h}^{-1}$ para o P1, P2 e P3, respectivamente. Em relação à textura, não houve grandes disparidades entre os perfis, embora as pequenas diferenças apresentadas na infiltração de água dos três perfis possam estar relacionadas à menor quantidade de fração fina (Tabela 1) apresentadas pelo P3. A menor infiltração do P2 pode ter relação com o maior número de fraturas no saprolito com ângulo de inclinação no sentido horizontal (Tabela 2), 
Tabela 1 - Profundidade, granulometria total com base na massa, granulometria da terra fina e relação silte/argila do horizonte A dos três perfis dos cinco Neossolos estudados.

\begin{tabular}{|c|c|c|c|c|c|c|c|c|}
\hline \multirow[b]{2}{*}{ Solo } & \multirow[b]{2}{*}{ Prof. (cm) } & \multicolumn{2}{|c|}{-----Granulometria (total)----- } & \multicolumn{4}{|c|}{----------------Granulometria (terra fina) ---------------- } & \multirow[b]{2}{*}{ Silte/Argila } \\
\hline & & Fração Grossa & Fração Fina & Areia Grossa & Areia Fina & Silte & Argila & \\
\hline N1P1 & $0-20$ & 630 & 370 & 81 & 243 & 462 & 214 & 2,2 \\
\hline N1P2 & $0-15$ & 487 & 513 & 135 & 225 & 438 & 202 & 2,2 \\
\hline N1P3 & $0-18$ & 675 & 325 & 95 & 235 & 443 & 227 & 1,9 \\
\hline N2P1 & $0-30$ & 378 & 622 & 139 & 248 & 387 & 225 & 1,7 \\
\hline N2P2 & $0-32$ & 348 & 652 & 134 & 443 & 278 & 145 & 1,9 \\
\hline N2P3 & $0-17$ & 350 & 650 & 208 & 373 & 303 & 116 & 2,6 \\
\hline N3P1 & $0-20$ & 221 & 779 & 148 & 207 & 417 & 228 & 1,8 \\
\hline N3P2 & $0-23$ & 201 & 799 & 106 & 216 & 424 & 254 & 1,7 \\
\hline N3P3 & $0-10$ & 274 & 726 & 134 & 247 & 404 & 215 & 1,9 \\
\hline N4P1 & $0-26$ & 343 & 657 & 110 & 169 & 449 & 272 & 1,7 \\
\hline N4P2 & $0-15$ & 268 & 732 & 167 & 146 & 398 & 290 & 1,4 \\
\hline N4P3 & $0-15$ & 408 & 592 & 132 & 172 & 458 & 238 & 1,9 \\
\hline N5P1 & $0-14$ & 522 & 478 & 47 & 145 & 514 & 294 & 1,8 \\
\hline N5P2 & $0-14$ & 625 & 375 & 38 & 174 & 500 & 287 & 1,7 \\
\hline N5P3 & $0-14$ & 606 & 394 & 77 & 177 & 473 & 273 & 1,7 \\
\hline
\end{tabular}

o que poderia estabelecer uma velocidade menor ao fluxo de água em comparação com o maior fraturamento no sentido vertical dos demais perfis, principalmente, no limite superior do saprolito.

Os perfis P1 e P2 de N2 apresentam comportamento semelhante da taxa de infiltração e da infiltração acumulada de água, contudo, diferindo do P3, que apresentou os maiores valores em todos os tempos avaliados. Já para a lâmina de água acumulada, a amplitude máxima se estabeleceu entre o P1, com 44mm, e o P3, com aproximadamente 726mm de água infiltrada (Figura 1B). Nessa área, a taxa básica de

Tabela 2 - Número, ângulo, espessura e preenchimento das fraturas da camada Cr nos três perfis dos cinco Neossolos estudados.

\begin{tabular}{|c|c|c|c|c|c|c|c|c|c|c|c|c|}
\hline \multirow{2}{*}{ Solo } & \multicolumn{2}{|c|}{------No frat.*------ } & \multicolumn{2}{|c|}{$----->45^{\circ}(\%)-----$} & \multicolumn{2}{|c|}{$---<45^{\circ}(\%)---$} & \multicolumn{2}{|c|}{ Espessura $(\mathrm{mm})^{* *}$} & \multicolumn{2}{|c|}{ Cheios $(\mathrm{mm}) * * *$} & \multicolumn{2}{|c|}{ Vazios $(\mathrm{mm})^{* * *}$} \\
\hline & $1 * * * *$ & $2 * * * *$ & 1 & 2 & 1 & 2 & 1 & 2 & 1 & 2 & 1 & 2 \\
\hline N1P1 & 8 & 8 & 13 & 63 & 87 & 37 & 56 & 20 & 34 & 16 & 13 & 4 \\
\hline N1P2 & 4 & 7 & 75 & 0 & 25 & 100 & 10 & 11 & 7 & 0 & 3 & 11 \\
\hline N1P3 & 6 & 6 & 0 & 33 & 100 & 67 & 13 & 8 & 9 & 3 & 4 & 5 \\
\hline N2P1 & 6 & 6 & 17 & 0 & 83 & 100 & 13 & 8 & 13 & 5 & 0 & 3 \\
\hline N2P2 & 5 & 3 & 0 & 33 & 100 & 67 & 8 & 5 & 2 & 2 & 6 & 3 \\
\hline N2P3 & 7 & 7 & 14 & 43 & 86 & 57 & 56 & 54 & 48 & 45 & 8 & 9 \\
\hline N3P1 & 5 & 1 & 0 & 100 & 100 & 0 & 9 & 10 & 5 & 10 & 4 & 0 \\
\hline N3P2 & 5 & 4 & 20 & 25 & 80 & 75 & 9 & 4 & 7 & 2 & 2 & 2 \\
\hline N3P3 & 7 & 9 & 28 & 22 & 72 & 78 & 15 & 13 & 10 & 6 & 5 & 7 \\
\hline N4P1 & - & 5 & - & 20 & - & 80 & - & 40 & - & 40 & - & 0 \\
\hline N4P2 & 3 & 3 & 33 & 33 & 67 & 67 & 12 & 15 & 12 & 15 & 0 & 0 \\
\hline N4P3 & 3 & 5 & 67 & 40 & 33 & 60 & 29 & 23 & 27 & 18 & 2 & 5 \\
\hline N5P1 & 6 & 8 & 17 & 0 & 83 & 100 & 10 & 18 & 10 & 18 & 0 & 0 \\
\hline N5P2 & 5 & 6 & 20 & 0 & 80 & 100 & 25 & 16 & 25 & 16 & 0 & 0 \\
\hline N5P3 & 9 & 10 & 44 & 10 & 56 & 90 & 36 & 16 & 36 & 16 & 0 & 0 \\
\hline
\end{tabular}

*Número de fraturas em uma linha horizontal de $40 \mathrm{~cm}$.

$* *$ Espessura total das fraturas.

$* * *$ Espessura das fraturas com e sem preenchimento.

**** Os números 1 e 2 representam duas linhas horizontais situadas a $20 \mathrm{~cm}$ uma da outra.

Ciência Rural, v.39, n.7, out, 2009. 
infiltração foi de aproximadamente 10 e $34 \mathrm{~mm} \mathrm{~h}^{-1}$ para o P1 e o P2, respectivamente, enquanto que, para o P3, foi de $164 \mathrm{~mm} \mathrm{~h}^{-1}$, valores menores que os encontrados no N1 e menores inclusive que os valores encontrados por SILVA (2003), de aproximadamente $30 \mathrm{~mm} \mathrm{~h}^{-1}$ para um Argissolo sob distintos estados de compactação.

Na tabela 1, verifica-se que o P3 do N2 apresentou menor espessura do horizonte $\mathrm{A}$, com $17 \mathrm{~cm}$, em relação aos 30 e 32cm, respectivamente, para o P1 e P2, além de menor conteúdo de argila e maior número e espessura de fraturas (Tabela 2), sugerindo a influência desses parâmetros na infiltração de água desses solos.

Como os Neossolos são pedogeneticamente pouco desenvolvidos, é de se esperar, portanto, que esse tipo de solo apresente grandes variações nos seus atributos químicos, físicos (PEDRON, 2007) e morfológicos (PEDRON et al., 2009), o que afetou, principalmente, o comportamento hídrico desses solos.
Na área N3, da mesma forma que no N1, houve comportamento homogêneo da infiltração de água entre os perfis analisados (Figura 1(C)). A semelhança das características físicas se refletiu na taxa de infiltração de água, que para esse solo se aproximou de 76, 56 e $50 \mathrm{~mm} \mathrm{~h}^{-1}$, respectivamente, em P1, P2 e P3, enquanto que a lâmina acumulada apresentou uma leve diferença, em que o P2 teve 369mm de água infiltrados, enquanto o P3 teve uma infiltração de 240mm de água após 180 minutos. As pequenas diferenças apresentadas no comportamento da água no perfil estão relacionadas principalmente com o maior número de fraturas de inclinação menores que $45^{\circ}$ em relação ao plano gravitacional para o P2 e o P3 (Tabela 2).

Na figura 2(A), percebe-se uma significativa disparidade na taxa de infiltração e infiltração acumulada de água em N4, principalmente para o P3,

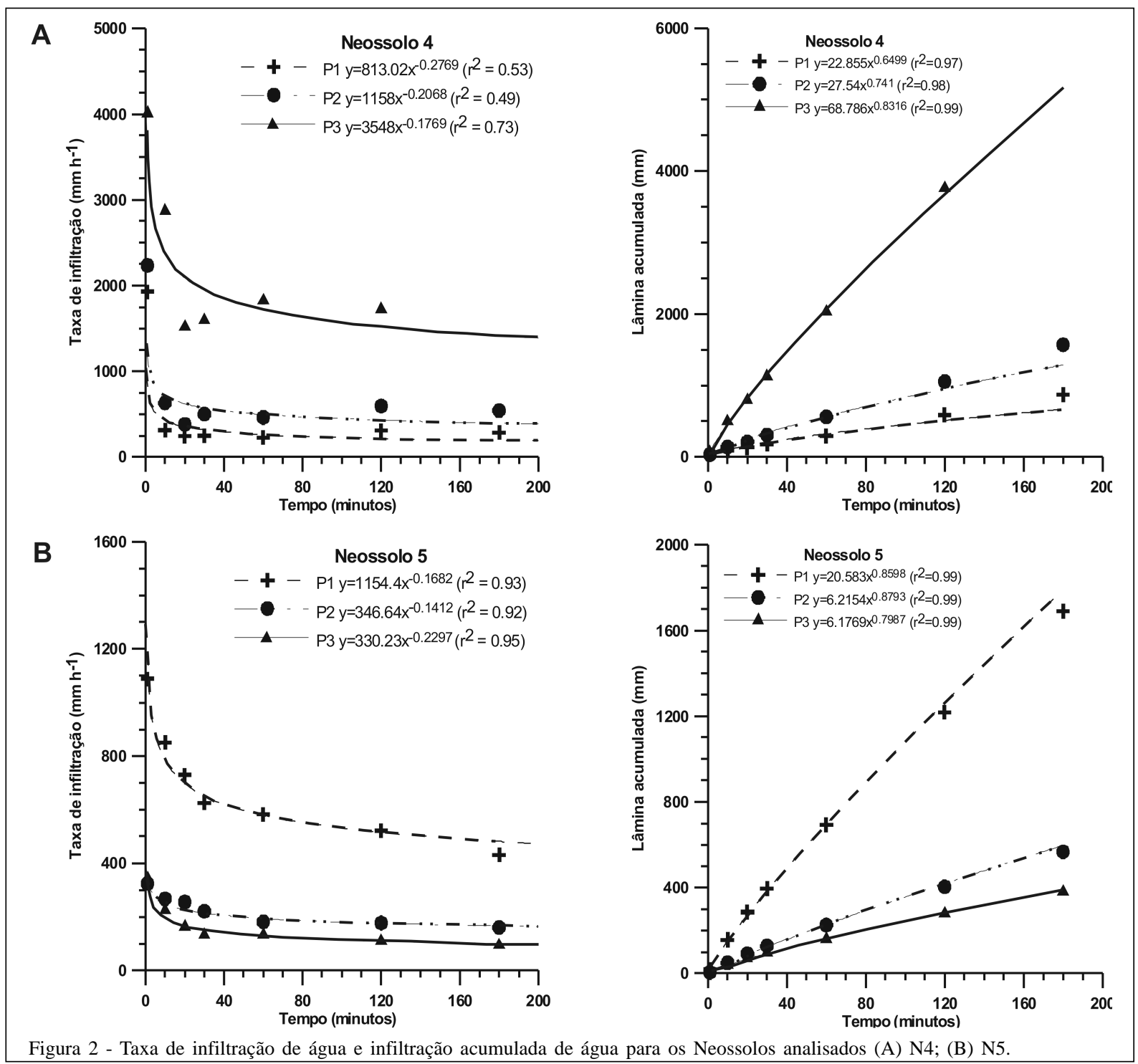

Ciência Rural, v.39, n.7, out, 2009. 
que apresentou valores mais elevados que os demais perfis. O P3 apresentou 5160mm de lâmina de água infiltrada, enquanto que no P1 foram infiltrados 871mm de água após 180 minutos. No entanto, os três perfis apresentaram apenas pequenas diferenças na quantidade de argila e fração fina de solo. A taxa básica de infiltração para os três perfis amostrados em N4 foi de 152, 305 e $953 \mathrm{~mm} \mathrm{~h}^{-1}$, respectivamente, para o P1, P2 e P3.

De modo geral, os solos localizados sob campo nativo (N2 e N3) apresentaram menor infiltração de água que os solos localizados sob mata (N1 e N4). Segundo SUZUKI et al. (2000), a presença de canais biológicos formados pela decomposição das raízes e pela ação da fauna do solo contribuem para as elevadas taxas de infiltração de água no solo. Comportamento semelhante foi obtido por MARTINS et al. (2006), que encontraram maiores valores médios da condutividade de água em um Nitossolo sob mata $\left(56,46 \mathrm{~mm} \mathrm{~h}^{-1}\right)$, em relação ao campo nativo $\left(42,48 \mathrm{~mm} \mathrm{~h}^{-1}\right)$.

Para a área N5, a taxa básica de infiltração no P1 foi de $388 \mathrm{~mm} \mathrm{~h}^{-1}$, enquanto que do P2 e do P3 foi, respectivamente, 161 e $96 \mathrm{~mm} \mathrm{~h}^{-1}$, mostrando uma amplitude superior a 300\%. A maior diferença entre a infiltração acumulada dos três perfis se deu entre o P1, que apresentou 1690mm infiltrados, e o P3, onde ocorreu uma infiltração de água na ordem de $380 \mathrm{~mm}$ (Figura 2B). Para esse solo, não foi encontrada relação entre a infiltração com as frações granulométricas e o fraturamento da camada saprolítica. Embora o P3 tenha apresentado maior número e espessura das fraturas, foi o que apresentou menor infiltração. A quantidade de fraturas no saprolito, que poderia ser um indicativo do potencial de infiltração, não foi suficiente para explicar esse fenômeno, uma vez que todas as fraturas do saprolito se encontram preenchidas com solo proveniente do horizonte superficial e fragmentos de saprolito em avançado grau de alteração.

Se comparados os dados de taxa básica de infiltração determinadas nos Neossolos deste trabalho com os dados obtidos para outras classes de solo, observa-se que estes foram significativamente maiores. LANZANOVA (2005) encontrou taxas de infiltração de 5 a $80 \mathrm{~mm} \mathrm{~h}^{-1}$ num Argissolo Vermelho-Amarelo, enquanto que SUZUKI et al. (2000) encontraram taxas de aproximadamente $85 \mathrm{~mm} \mathrm{~h}^{-1}$ em um Latossolo submetido a preparo convencional.

O comportamento da infiltração de água deixa claro que diferentes Neossolos apresentaram grandes diferenças em seus atributos físicos e morfológicos, mesmo quando comparados os perfis de uma mesma área de coleta. Além disso, verificou-se que, mesmo em perfis que apresentam classificação idêntica até o quarto nível categórico, como neste caso, houve grandes variações no comportamento hídrico, deixando claro que uma correta determinação do potencial de uso desses solos somente será possível com uma descrição mais detalhada do seu comportamento físico-hídrico.

A variação multidimensional dos dados analisados (Figura 3) mostra uma ordenação de quatro grupos distintos de solos, além do comportamento irregular dos perfis, e comprova a estreita relação entre a infiltração de água no solo e os ângulos das fraturas em relação ao plano gravitacional, com a fração grosseira de solo e relação inversa, com as frações finas de solo. Percebe-se também que o número de fraturas no saprolito não apresentou grande relação com a infiltração de água, devido ao preenchimento destas com solo. No entanto, algumas características físicas e morfológicas, isoladamente, não foram suficientes para explicar o fenômeno da infiltração de água. Em alguns perfis, como no P3 do N1, esse fenômeno teve relação com a granulometria da fração fina, em outros, como no P2 do N1, com o fraturamento do perfil e no caso do P3 do N2, com o teor de argila e com o fraturamento da camada saprolítica.

A classe dos Neossolos, devido a sua grande variabilidade, precisa ser mais bem definida no SiBCS, principalmente, no terceiro e no quarto nível categórico. Informações como as obtidas neste trabalho mostram grandes diferenças entre esses solos, apesar de todos serem classificados como Neossolos Regolíticos Eutróficos típicos.

\section{CONCLUSÃO}

Na avaliação da infiltração de água em Neossolos Regolíticos e nas condições pedoclimáticas da região onde foi desenvolvido este trabalho, concluise que os Neossolos Regolíticos apresentam grandes diferenças na taxa de infiltração e infiltração acumulada de água no solo, quando encontrados em distintos ambientes, e até mesmo quando comparados perfis alocados a distâncias inferiores a três metros entre si.

Além disso, as diferenças na infiltração de água para os Neossolos estudados estão relacionadas às frações granulométricas do solo, à quantidade, à espessura, ao ângulo e ao preenchimento das fraturas da camada saprolítica e às condições de relevo e uso atual do solo. Quando consideradas isoladamente, essas propriedades apresentam limitações na indicação da infiltração de água em alguns perfis estudados.

Ciência Rural, v.39, n.7, out, 2009. 


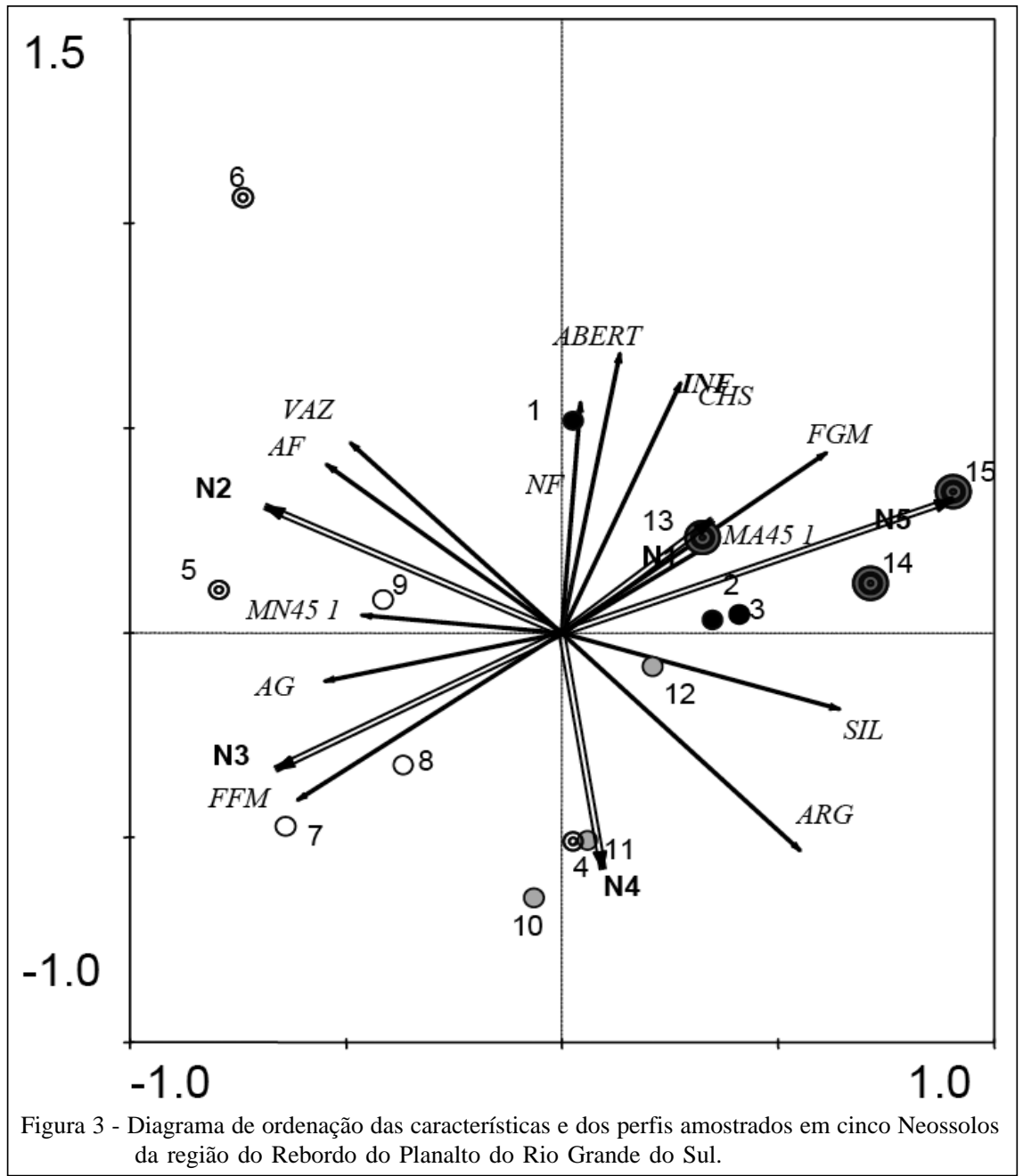

\section{REFERÊNCIAS}

BRASIL, Ministério da Agricultura. Levantamento de reconhecimento dos solos do Rio Grande do Sul. Recife, 1973. 431p. (Boletim técnico n.30).

CAUDURO, F.A.; DORFMAN, R. Manual de ensaios de laboratório e de campo para irrigação e drenagem. Porto Alegre: PRONI-IPH-UFRGS, 1986. 216p.

EMBRAPA. Manual de métodos de análise de solos. 2.ed. Rio de Janeiro: EMBRAPA, 1997. 221p.

Sistema brasileiro de classificação de solo. 2.ed. Rio de Janeiro: EMBRAPA, 2006. 306p.

LANZANOVA, M.E. Atributos físicos do solo em sistemas de culturas sob plantio direto na integração lavourapecuária. 2005. 125f. Dissertação (Mestrado em Ciência do Solo) - Universidade Federal de Santa Maria, Santa Maria.

MALUF, J.R.T. Nova classificação climática do Estado do Rio Grande do Sul. Revista Brasileira de Agrometeorologia, v.8, p.141-150, 2000.
MARTINS, G.C. et al. Campos nativos e matas adjacentes da região de Humaitá (AM): atributos diferenciais dos solos. Ciência e Agrotecnologia, v.30, p.221-227, 2006. Disponível em: <http://dx.doi.org/10.1590/S1413-70542006000200005>. Acesso em: 06 maio 2009. doi: 10.1590/S1413-70542006000200005.

OLIVEIRA, J.B. Pedologia aplicada. Jaboticabal, FUNEP, 2001. 414p.

PEDRON, F.A. Mineralogia, morfologia e classificação de saprólitos e Neossolos derivados de rochas vulcânicas no Rio Grande do Sul. 2007. 160f. Tese (Doutorado em Ciência do Solo) - Universidade Federal de Santa Maria, Santa Maria.

PEDRON, F.A. et al. Morfologia e classificação taxonômica de Neossolos e saprolitos derivados de rochas vulcânicas da Formação Serra Geral no Rio Grande no Sul. Revista Brasileira de Ciência do Solo, v.33, p.119-128, 2009. Disponível em: $<$ http://dx.doi.org/10.1590/S0100-06832009000100013>. Acesso em: 06 maio 2009. doi: 10.1590/S0100-06832009000100013.

SANTOS, R.D. et al. Manual de descrição e coleta de solos no campo. 5.ed. Viçosa: SBCS, 2005. 100p. 
SILVA, V.R. Propriedades físicas e hídricas em solos sob diferentes estados de compactação. 2003. 171f. Tese (Doutorado em Ciência do Solo) - Universidade Federal de Santa Maria, Santa Maria.

STRECK, E. V. et al. Solos do Rio Grande do Sul. 2.ed. Porto Alegre: Emater/RS-ASCAR, 2008. 222p.

STÜRMER, S.L.K. Infiltração de água em Neossolos Regolíticos do rebordo do Planalto do Rio Grande do Sul. 2008. 104f. Dissertação (Mestrado em Ciência do Solo) - Universidade Federal de Santa Maria, Santa Maria.
SUZUKI, L.E A.S. et al. Alteração na infiltração de água de um Latossolo vermelho-amarelo do noroeste do estado de São Paulo sob sistema de preparo convencional. Revista de Iniciação Científica, v.2, p.57-63, 2000.

ter BRAAK, C.J.F.; SMILAUER, P. CANOCO reference manual and canodraw for Windows user's guide: software for canonical community ordination (version 4.5). Ithaca, New York: Microcomputer Power, 2002. 500p.

WHITE, A.F.; BRANTLEY, S.L. Chemical weathering rates of silicate minerals. Washington, USA: Mineralogical Society of America, 1995. 583p. 